\title{
A sustainable biogas model in China: the case study of Beijing Deqingyuan biogas project
}

\author{
Lihong Chen ${ }^{\mathrm{a}, \mathrm{b}}$, Rong-Gang Cong ${ }^{\mathrm{b}, *}$, Bangrong Shu ${ }^{\mathrm{a}}, \mathrm{Zhi}^{\mathrm{F}} \mathrm{Fu} \mathrm{Mi}^{\mathrm{c}}$

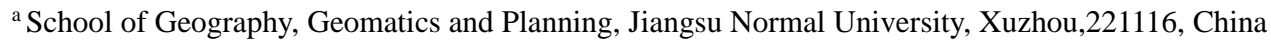 \\ b Department of Environmental Science, Aarhus University, Roskilde, DK-4000, Denmark \\ c Tyndall Centre for Climate Change Research, School of International Development, University of East Anglia, \\ Norwich NR4 7TJ, UK
}

\begin{abstract}
According to the Paris Agreement, China has the ambition to develop non-fossil energy which will account for $20 \%$ of the total energy consumption in 2030 . China has abundant biomass potential implying the bioenergy should be an important option of non-fossil energy. In this analysis, we present an representative biogas project (the Deqingyuan project, DQY) in Beijing and conduct a cost-benefit analysis for the whole value chain. DQY is the first large-scale biogas project in China that utilizes $100 \%$ chicken manure as a feedstock and integrates biogas production with ecological agriculture using advanced technologies. DQY uses 80,000 tons of chicken manure and 100,000 tons of sewage each year to produce biogas, which generates 14 million KWh of power annually, and obtains an additional revenue of RMB 8 million yuan each year through the Clean Development Mechanism (CDM). Operating as an exemple of a sustainable bioenergy model, DQY accomplishes the full use of a recycled resource while showing consideration for animal welfare during the entire production, which is a fundamental component of the new rural energy strategy. The circular economy model of DQY plays a prominent role in reducing greenhouse gas emissions, mitigating pollution, and increasing employment, among other benefits. This paper aims to conduct a comprehensive analysis of the typical demonstration model (DQY) in utilization of agricultural waste in China, and further proposes a general development model of Chinese biogas in the future.
\end{abstract}

Keywords: Biogas project; Biomass energy; Cost-benefit analysis; Circular economy; Renewable

\footnotetext{
* Corresponding author. Tel.:+ +46769822582

E-mail address: rc@envs.au.dk

Address: Department of Environmental Science, Aarhus University, Frederiksborgvej 399, 4000, Roskilde, Denmark
} 
energy policy; Sustainability

\section{Introduction}

Renewable energy has become an important strategic solution for addressing climate change and energy crisis while achieving sustainable development (Cong, 2013; He et al., 2016). Many countries have committed to decreasing their emissions and securing the energy supply through promoting the development of renewable energy (Cong and Shen, 2014; Hua et al., 2016). Biomass energy is one of humanity's earliest sources of energy, particularly in rural areas, where it is often the only accessible and affordable source of energy (Demirbas, 2004). Although China has the large potentials to develop bioenergy with abundant biomass resources (Jiang et al., 2012), its development and utilization are still very low. In 2014, the development and utilization of biomass in China was equivalent to 18.68 million tons of standard coal (58\% as biogas, $9.4 \%$ as bioethanol, $8.1 \%$ as biodiesel and $24.36 \%$ as biomass power), only accounting for $0.56 \%$ of total primary energy consumption in China (Minister of Agriculture, 2015).

A circular economy refers to an economic production model in which the resource or feedstock used for production gains use value one more time through practices such as circular regeneration to enable the utilization of recycled materials, while reducing waste disposal (Andersen, 2007). A circular economy may be able to achieve a "win-win-win" situation by linking economic development, environmental improvement and structural optimization (Chang et al., 2011), and this model has been implemented as a national policy of sustainable development in China (Geng et al., 2012). Biogas is a renewable energy that is worth promoting in this context (Cong et al., 2017). Organic manure such as livestock manure is an important resource for biogas production and could provide a sustainable source of energy (Bruni et al., 2010; Jiang et al., 2011). Combining a biogas project with ecological agriculture is an important trend in developing a circular economy, and various model systems have been developed. Karpenstein-Machan (2001) proposed a model termed a "self-sustained farm", while Chinese examples include a "livestock-biogas-fruit" 
model (Chen, 1997) and "pig-biogas-vegetable" model (Qi et al., 2005). Chen (2010) categorizes the rural-household-biogas-related ecological agriculture in China into operational classifications such as "pigpen-toilet-biogas digester", "pigpen-toilet-biogas digester-solar greenhouse" and "toilet-biogas digester-solar powered barns-water cellar-water saving irrigation" systems. Even remote areas in China, such as the Tibet Autonomous Region, promote the "residence biogas model" as a sustainable system (Feng et al., 2009). Currently, European biogas technology is the most advanced and mature that has widespread application (Chang et al., 2011). Raw materials including livestock manure for producing biogas are derived primarily from pigs and cattle, which has been widely used for practical production as well as studies in the laboratories (Carrère et al., 2009; Castrillón et al., 2011; Chae et al., 2008). The study about biogas production using chicken manure is primaryly confined to the laboratory (Abouelenien et al., 2010), and chicken manure-based biogas projects are relatively rare in China. One important reason is that chicken manure has a high concentration of nitrogen in the substrate, implying a low carbon-nitrogen $(\mathrm{C} / \mathrm{N})$ ratio (around 7-8:1) (Wang et al., 2012). The $\mathrm{C} / \mathrm{N}$ ratio is important for production efficiency of biogass and the optimal range should be between 20:1 and 30:1 (Gao et al., 2010).

The Deqingyuan (DQY) biogas project in Beijing is the first large-scale biogas project in China that utilizes $100 \%$ chicken manure as a feedstock. It removes ammonia $\left(\mathrm{NH}_{3}\right)$ by recycling and washing of biogas in sulfuric acid (Abouelenien et al., 2010). With this biogas project, the DQY Company closely connects livestock farming, plantations, surrounding households, and markets, forming a demonstrative model of a circular economy. The most distinctive feature of this model is the maximization of resource use, realizing the maximum conversion of livestock manure to energy while simultaneously reducing manure pollution into the environment and creating a prototypical model of contract agriculture.

\section{Biogas projects in China}

There are three primary categories of biogas projects in China: rural household-, 
agricultural waste- and industrial organic waste based biogas projects. By the end of 2014, there were as many as 35,533,000 rural households in China using biogas, accounting for $30 \%$ of the suitable households. In 2014 the total annual production of biogas in China reached 15.5 billion $\mathrm{m}^{3}$, among which total biogas produced in rural areas reached 13.24 billion $\mathrm{m}^{3}$, with an annual each household production of $373 \mathrm{~m}^{3}$; 103,036 agricultural waste disposal projects, which produced 2 billion $\mathrm{m}^{3}$ of biogas; and 320 industrial waste disposal projects, which produced 0.25 billion $\mathrm{m}^{3}$ of biogas. Additional, some small biogas projects were scattered among schools and hospitals (Minister of Agriculture, 2015).

Along with the development of livestock operations in China and the application of biogas projects to agricultural waste disposal, agricultural biogas projects have developed tremendously not only in terms of the total quantity production (Fig. 1) but also in terms of their proportions in the total biogas production (Fig. 2). Total biogas production from agricultural projects increased from 40 million $\mathrm{m}^{3}$ in 2001 to 2 billion $\mathrm{m}^{3}$ in 2014 . The proportion of agricultural biogas project in total biogas production in China has increased from $1.11 \%$ in 2001 to $12.93 \%$ in 2014.

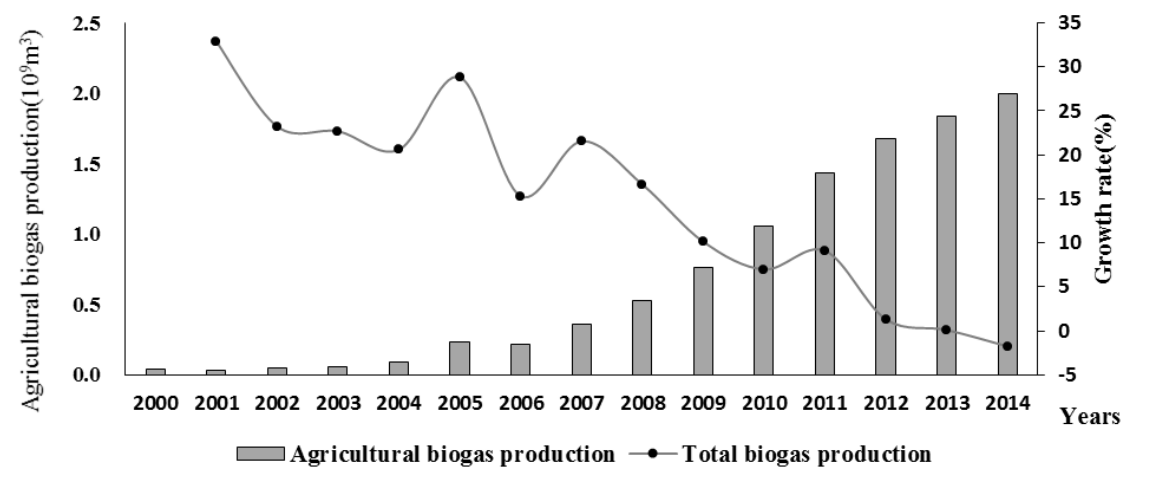

Fig. 1. Biogas production from agricultural biogas projects in China from $2001-2014\left(10^{9} \mathrm{~m}^{3}\right)$ 

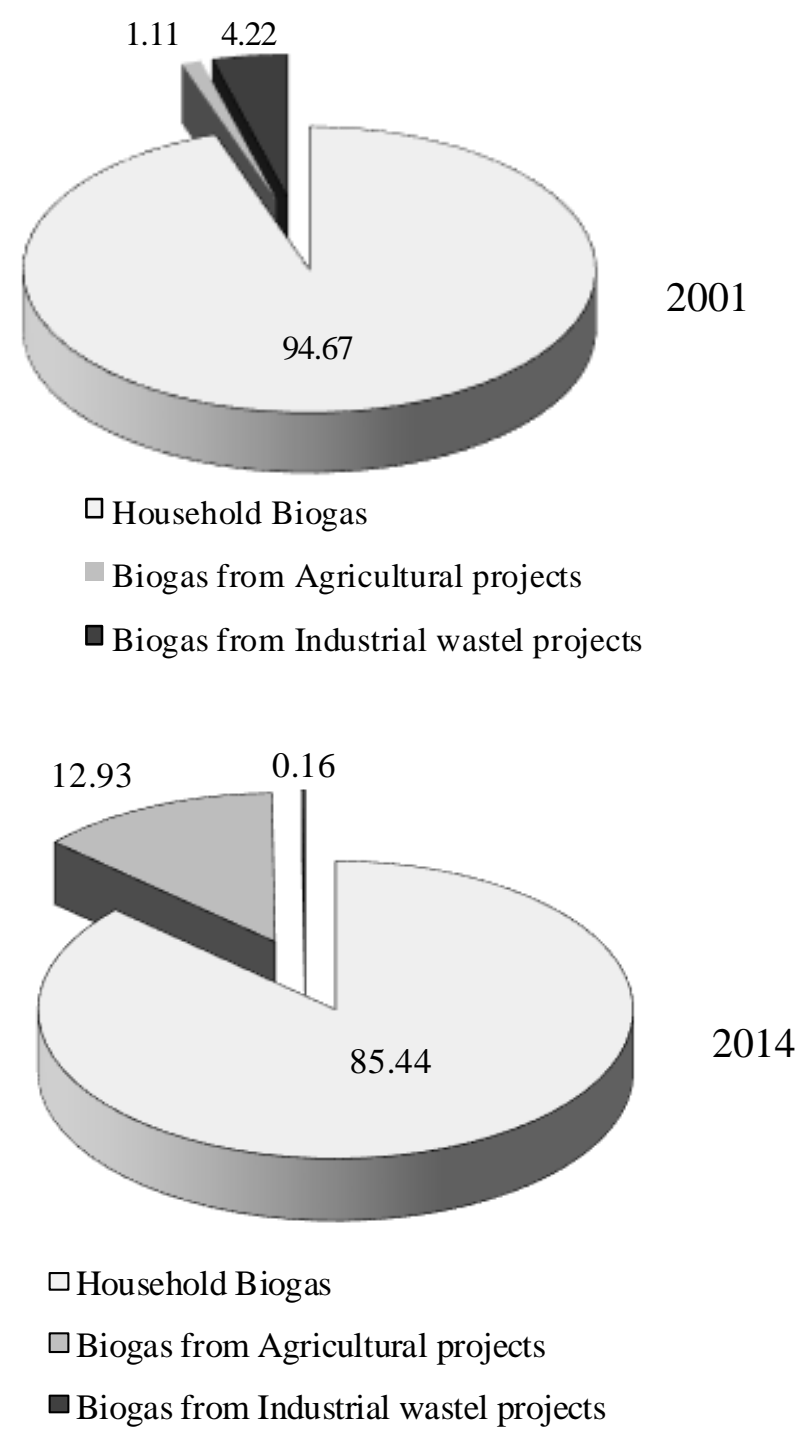

Fig. 2. The proportion of biogas components in China in 2001 and 2014 (unit: \%) Household biogas provides large quantities of renewable energy to rural areas in China. However, constrained by limited funds and technology, such small-scale operations have shortcomings such as low comprehensive use rates and high scrap rates of biogas tanks. In 2014, there were as many as 332,117 discarded household biogas tanks [5]. Medium-and-large-scale biogas projects, alternatively, could not only increase the production efficiency but also increase companies' benefits, utilize resources in a comprehensive way and produce energy more efficiently.

The paper aims to conduct a comprehensive analysis for a typical demonstration model (DQY) in utilization of agricultural waste, and further propose an innovative comprehensive development model of Chinese biogas in the future. 


\section{Data and Methods}

\subsection{Data collection}

The procedure was as follows:

(1) We designed a survey form and sent it to the principal of DQY biogas project. The survey form included: the initial investment, operating costs, annual income and expenditure, production process, environmental emissions and treatment etc.

(2) We made a field survey in 2014, and further discussed the data and materials of the DQY biogas project with stakeholders. So all the data of DQY biogas project in this paper has been verified.

(3) The data of Chinese biogas and others renewable energies were from the public statistics.

\subsection{Methods}

We use the environmental cost-benefit analysis (CBA) to take both the market and non-market goods into account (Cong and Termansen, 2016) as the quantitative part and conceptual construct as the qualitative part.

(1) Calculation of the proportions of investment and expenditure. The final results were approved by the principal of DQY biogas project.

(2) Evaluation of the circular economy of DQY ecological farm by field survey and drawing the frame chart.

(3) According to the status of China's biogas development and the need of greenhouse gas emissions we design a new comprehensive development model of Chinese biogas in the future.

\section{Results}

The Beijing DQY Agriculture Technology CO. Ltd (Beijing DQY Ecological Farm), covering an area of 67 hectares, is located adjacent to Beijing Songshan National Nature Reserve. The DQY biogas project is an important part of the ecological farm. As the largest egg farm in Asia, DQY produces 80,000 tons of chicken manure and 100,000 tons of sewage each year. If manure and sewage are not properly handled, serious environmental issues could occur. By applying an advanced technology to 
produce high concentration fermentation, DQY solves the problem of chicken manure and sewage disposal while creating significant economic, social and environmental benefits. As a commercial model to comprehensively utilize its resource, DQY integrates livestock farming, biogas, row crops and organic fertilizer, and is equipped with the most advanced technologies in China which enable it recycle poultry and livestock manure, promote renewable energy and contribute sustainable development.

\subsection{Technological process}

The livestock operation portion of the biogas project refers to a production facility that performs anaerobic digestion of the livestock manure and sewage, enabling biogas production and pollution reduction. The technological process of DQY biogas project consists of five main components: pretreatment of raw materials, biological desulphurization, a power grid, biogas for household use and biogas digestate for fertilization of agricultural crops (Fig. 3). Monitoring the management of biogas production is performed during the entire process.

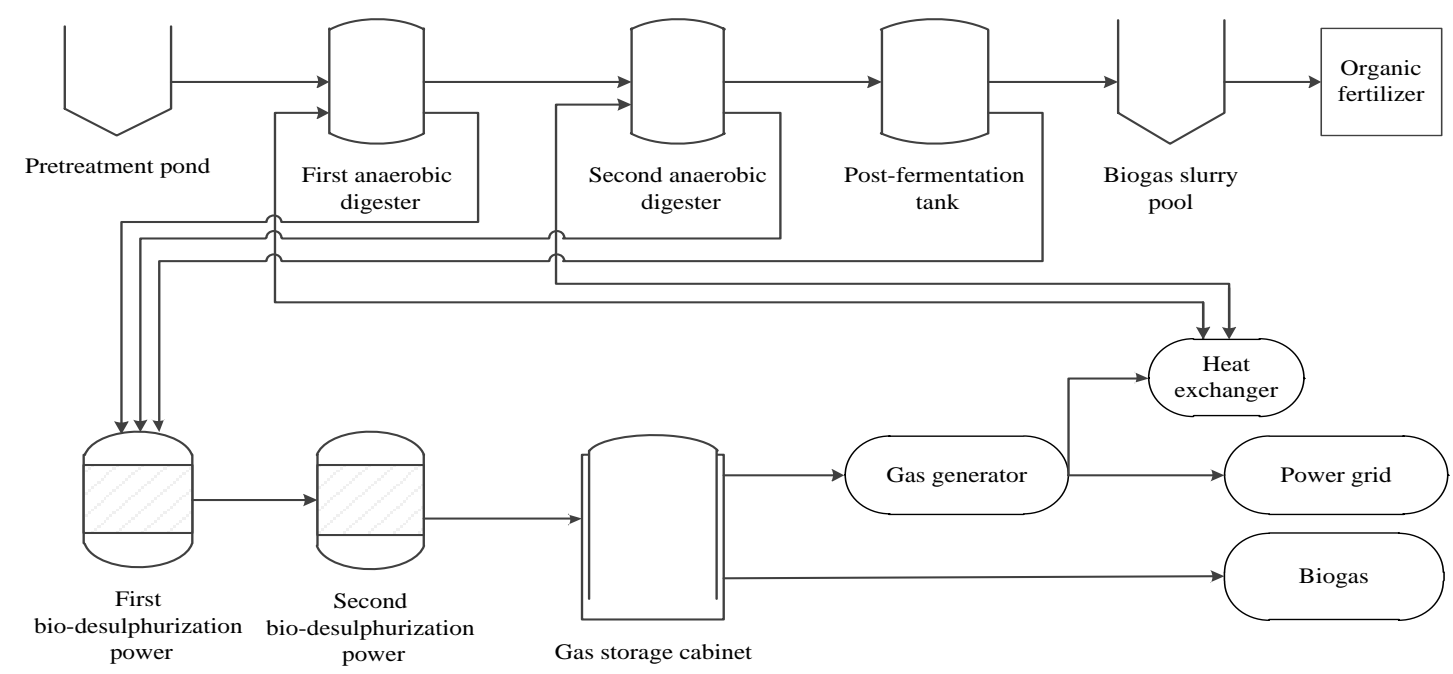

Fig. 3. Flow chart of production process in the DQY biogas project

As one of the most important components of the DQY Ecological Farm, the biogas project has integrated the most advanced technology into the biogas production process.

\subsubsection{Biogas fermentation pretreatment device}

Sand, which accounts for 8 percents of chicken manure, is mixed with digested liquid manure implying it is difficult to separate sand from the mixture. However, 
unless sand is separated from the manure, shell powder and sand will be deposited in the anaerobic tank and clog up the pipeline, making the fermentation process less efficient. Using a self-developed spiral sand-removing system and a middle-temperature hydrolysis process, $80-90 \%$ percent of the sand can be successfully removed, solving the problems of blockage in material transfer pipelines and deposition in the fermentation tank, which enables the process operate smoothly.

\subsubsection{Fermentation technology}

Anaerobic fermentation, accomplished in a Continuous Stirred-Tank Reactor (CSTR), uses high manure concentrations and medium temperatures. Mixing and heating technologies are both used in the methane fermentation tank (two important technological breakthroughs in the methane fermentation process), which allows raw materials and micro-organisms to be mixed completely and thus greatly increases the rate of methane fermentation. This technology features low energy consumption, high processing capacity and biogas production volumes, easy management and operation, and low production cost. Rapid anaerobic fermentation technology, as the most robust and effective industrialization technology among the constructed projects at DQY, is not subject to climate or geographical conditions.

\subsubsection{Biogas purification and desulfurization process}

Before methane can be burned directly or used to generate electricity, it must be pre-treated through a desulfurization process. The DQY system has implemented a biological desulfurization process. Through the action of colorless sulfur bacteria, the oxidation states of sulfur pollutants are transformed into sulfide $\left(\mathrm{H}_{2} \mathrm{~S}\right)$ by bio-reduction and then converted into sulfur though a biological oxidation process. Through two bio-desulfurization processes, the $\mathrm{H}_{2} \mathrm{~S}$ content in the biogas is reduced from $1000 \mathrm{ppm}$ to less than $10 \mathrm{ppm}$. Biological desulfurization is characterized by the following technical advantages: devoid of catalysts and oxidants (air excluded), no disposal of chemical sludge, low biological pollution, low energy consumption, highly-effective sulfur recovery and odorless.

\subsubsection{Integrated solid-liquid processing technology}

DQY has adopted the most advanced technologies, including biodegradation, 
solid-liquid separation, membrane separation, enabling it achieve residue, biogas slurry and waste water integrated treatment while efficiently producing high quality organic fertilizer and re-usable clean water.

\subsection{Economic, environmental and social benefits of the DQY biogas project}

\subsubsection{Economic benefits of the DQY biogas project}

(1) Economic benefit analysis without considering reductions in greenhouse gas emissions

The initial investment of the DQY project reached RMB 65 million yuan, and the designed operational life was 30 years. Table 1 listed all the items of the investment.

Table 1 Initial investment of DQY biogas project

\begin{tabular}{|c|c|c|}
\hline Item & $\begin{array}{l}\text { Investment } \\
\left(10^{4} ¥\right)\end{array}$ & Percentage \\
\hline 1 Manure pretreatment system & 700 & $10.77 \%$ \\
\hline 2 Anaerobic digestion system & 1800 & $27.69 \%$ \\
\hline 3 Biogas utilization system & 2200 & $33.85 \%$ \\
\hline $\begin{array}{l}4 \text { Solid manure/biogas residue (producing organic } \\
\text { fertilizer )system }\end{array}$ & 560 & $8.62 \%$ \\
\hline 5 Subsidiary facilities & 500 & $7.70 \%$ \\
\hline 6 Land use costs & 30 & $0.46 \%$ \\
\hline $\begin{array}{l}7 \text { Public facilities (fire control, roads and } \\
\text { landscaping, etc.) }\end{array}$ & 10 & $0.15 \%$ \\
\hline 8 Power supply system & 500 & $7.69 \%$ \\
\hline 9 Other costs (design fee and contingency fee) & 200 & $3.08 \%$ \\
\hline Total & 6500 & $100 \%$ \\
\hline
\end{tabular}

Although the benefits of greenhouse gas emission reductions are not taken into consideration, the economic benefits of the DQY biogas project include both direct and indirect economic benefits. Direct economic benefits include earnings from 
biogas power generation and the sale of digestate as fertilizer. Indirect economic benefits are non-monetary benefits including the ability to discharge sewage that does not require treatment and improved post-biogas process water quality; hence, livestock farms can avoid heavy penalties. Currently, DQY generates 14 million KWh of power from biogas annually with a unit price of approximately RMB 0.6 yuan/KWh; the profit from power generation is RMB 8.4 million yuan each year. The annual yield of biogas fertilizer is 6600 tons and the sales profit is RMB 2 million yuan. By improving the quality of discharged water, the poultry farm is able to reduce the amount of their discharge penalties (RMB 2 yuan/ton) and save RMB 200,000 yuan each year. As a result, the total economic benefits of the DQY biogas project can reach RMB 10.6 million yuan per year.

The operating costs of the DQY biogas project are approximately RMB 6 million yuan each year (Table 2) and mainly include maintenance, labor, management, energy consumption and materials (accessories). Due to the installation of a fully-automatic chicken manure collection and transport system as well as the biogas production and power generation system, maintenance costs for the DQY biogas project comprise approximately $40 \%$ of total annual operating costs. After deducting the operating cost, the net economic profits of the DQY biogas project are RMB 4.6 million yuan per year and the anticipated static payback period is 14.13 years.

Table 2 Operating costs for the DQY biogas project

\begin{tabular}{|c|c|c|}
\hline Item & $\begin{array}{l}\text { Running cost }\left(10^{4}\right. \\
¥)\end{array}$ & Percentage $(\%)$ \\
\hline 1 Maintenance costs & 240 & $40.00 \%$ \\
\hline 2 Labor costs & 50 & $8.33 \%$ \\
\hline 3 Management expenses & 50 & $8.33 \%$ \\
\hline 4 Energy consumption costs & 60 & $10.00 \%$ \\
\hline 5 Materials (accessories) costs & 200 & $33.33 \%$ \\
\hline Total & 600 & $100 \%$ \\
\hline
\end{tabular}


(2) Economic benefit analysis while considering reducing greenhouse gas emission

DQY is the first agricultural enterprise in China to be approved by the Clean Development Mechanism (CDM). CDM is one of the flexible mechanisms introduced by the Kyoto Protocol (Cong and Wei, 2012; Sutter and Parreño, 2007). CDM permits the contracting parties (mainly developed countries) and non-contracting parties (mainly developing countries) to jointly carry out greenhouse gas emission reduction projects. The reduced emissions from these projects can be considered a restricted emission amount or a reduced emission amount as promised by the contracting countries. For developed countries, CDM provides a type of flexible mechanism to abide by the contract. For developing countries, CDM is able to provide partial funding and advanced technologies. Thus, CDM is widely regarded as a win-win mechanism (Matsuo, 2003).

CDM projects are predominantly greenhouse gas emission reduction projects implemented in developing countries to accomplish the emission reduction goals of developed countries. According to the World Bank, the Dutch government and DQY Company calculations, annual reductions in greenhouse gas emissions are equivalent to 84,000 tons of $\mathrm{CO}_{2}$ (the baseline and methodologies to calculate greenhouse gas emission reduction are protected by the CDM contract and are considered by DQY to be intellectual property; therefore, detailed discussion has been omitted from the present paper). DQY currently acquires gains corresponding to a subsidy of RMB 8 million annually for reduced greenhouse gas emissions. With this revenue, the net economic profit reaches RMB 12.6 million yuan per year, and the static payback period is reduced to 5.16 years, which significantly shortens the investment payback time of the DQY biogas project.

\subsubsection{Environmental and social benefits of the DQY biogas project}

(1) Reducing emission of greenhouse gases

Energy plays a vital role in increasing socio-economic development and improving 
standard of living for people (Gokcol et al., 2009). Energy security problems have occurred since the industrial revolution. While enjoying the benefits brought out by energy such as economic development, technological progress and other interests, people also experience a variety of unavoidable challenges. The extensive use of fossil fuels generates considerable greenhouse and other harmful gases. It is widely accepted worldwide that global warming is by far the greatest threat and challenge (Shuit et al., 2009). Due to the warming effect caused by $\mathrm{CO}_{2}, \mathrm{CH}_{4}, \mathrm{~N}_{2} \mathrm{O}$ and other greenhouse gases, it is important to substitute fossil fuels by renewable energy sources.

In order to meet the reduction goal of greenhouse gas emissions and mitigate the utilization of fossil energy, it is imperative to improve the energy structure. Development and utilization of biomass energy is an excellent way to reduce greenhouse gas emissions. The reduction in greenhouse gas emissions by DQY is not only profitable in economic terms but also beneficial for society that can reduce a total of 84,000 tons of $\mathrm{CO}_{2}$ annually. If this technology is extended and promoted, and enterprises utilize energy resources in a comprehensive manner by adopting a circular economy model, the annual emission reductions in China could be tremendous.

\section{(2) Reducing pollution}

The 80,000 tons of chicken manure and 100, 000 tons of sewage produced by DQY each year would seriously pollute the environment if not properly treated, and the company would be subject to heavy penalty fines. Although the advanced technology used by DQY increases investment costs, it is beneficial for pollution mitigation. The initial chemical oxygen demand (COD) concentration of the manure-sewage-mixture on the DQY poultry farm was $18,000-24,000 \mathrm{mg} / \mathrm{l}$ and the biochemical oxygen demand (BOD) concentration was $4,600 \mathrm{mg} / \mathrm{l}$. Using advanced technology, DQY achieves COD and BOD removal rates of $64 \%$ and $70 \%$, respectively. The annual removal quantity of gravel in manure is 2600 tons, with a removal rate of $89 \%$.

\section{(3) Providing employment}


Operating a biogas project that adopts advanced fermentation technology requires a large number of skilled workers [9]. The DQY Ecological Garden employs roughly 400 skilled workers, among whom 10 workers are engaged in the biogas project. In the current situation job market where graduates from universities and secondary schools have difficulty in finding employment, hiring a large number of workers would effectively relieve the pressure of unemployment. Alternatively, a great number of workers with specialized knowledge would promote technology upgrades and production efficiency for the DQY Company.

\subsection{Circular economy of DQY Ecological Farm}

4.3.1 Flow chart of the comprehensive use of biomass energy by DQY Ecological Farm

The DQY Ecological Farm has a comprehensive resource utilization model that integrates poultry farming, biogas, agricultural crops and fertilizer production (Fig. 4). DQY maintains nearly 3 million chickens annually. In 2014, DQY earned as much as RMB 350 million yuan from eggs and RMB 80 million yuan from CDM (Approved consolidated methodologies: ACM0010). The poultry operation provides material for the biogas project. The biogas is not only used for power generation but is also provided to adjacent households for free. Part of the fertilizer produced in the biogas operation is sold and part of it is used on the ecological farm. The DQY Ecological Garden adopts ecological agriculture practices and prevents pesticides from polluting vegetables. The biogas digestate provided to neighboring farmers improves soil fertility and promotes the growth of maize. The unpolluted maize is sold to the DQY Ecological Farm as chicken fodder. Apart from selling eggs and chicken meat, the deep processing of eggs prior to selling improves the value of eggs and increases benefits for the company. 


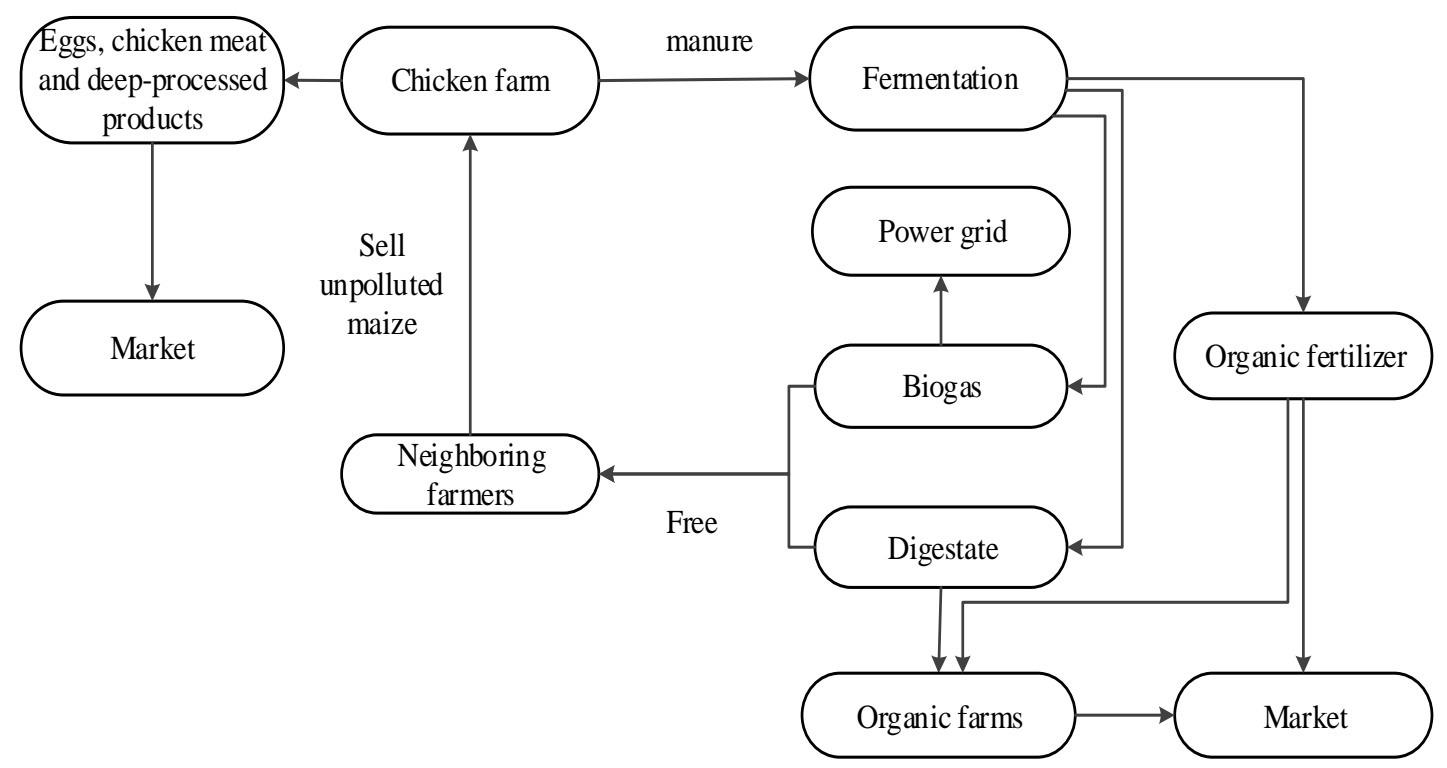

Fig. 4. The comprehensive resources utilization model of DQY Ecological Farm

\subsubsection{Evaluation of the circular economy of DQY Ecological Farm}

(1) A Paragon of circular economy that combines a biogas project with ecological

\section{agriculture}

The large population of people living in rural China without access to clean energy is a serious issue for energy poverty and sustainable development. Circular economy and ecological agriculture are key ways to solve this problem (Balachandra, 2011). As mentioned above, there are presently many models embracing biogas projects and ecological agriculture in China. The DQY Ecological Farm has the complete ecological chain and full energy utilization; an exemplary representative for the circular economy model (Fig. 5). DQY annually produces 6600 tons of solid fertilizer, 140,000 tons of fluid fertilizer, 60,000 tons of organic maize and 25,000 tons of organic fruits. The plant supplies $730,000 \mathrm{~m}^{3}$ of biogas to adjacent households, and the comprehensive use of surplus heat is equivalent to saving 4500 tons of standard coal each year. 


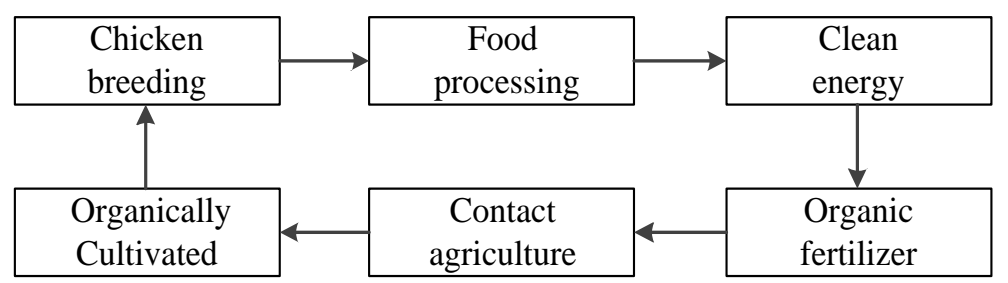

Fig. 5. Flow chart of the circular economy of DQY Ecological Farm

During the entire ecological economic process of the DQY Company, an innovative model of contract agriculture has been adopted. Contract agriculture, also known as contract farming, includes agricultural products orders and agreements. DQY, by way of contract agriculture, purchases organic maize from local farmers, and on average provide 60,000 households with 56 million RMB income per year. The organic maize is processed into nutritional feed in the chicken feed factory. Combined with strict processing and transport measure, the product is used as feed for DQY pullet and laying hens.

\section{(2) A representative low carbon model}

Under a low-carbon model, enterprises adopt new technologies to reduce greenhouse gas emissions and use new materials and procedures to improve or innovate operational activities to achieve greenhouse gas emission reductions to the greatest extent while generating new operational models. Using the model of biogas power generation, the DQY biogas project collects methane from chicken manure fermentation and generates power. Each year, a total of 84,000 tons of $\mathrm{CO}_{2}$ are reduced. The DQY company produces 500,000,000 eggs every year, and the production of each DQY egg is equivalent to a reduction of 168 grams of carbon dioxide emissions, and being at forefront of low-carbon economy. DQY urges consumers to participate in the low-carbon actions. By the entire process, the DQY Ecological Farm represents a low-carbon model.

\section{(3) Consistency with the rural renewable energy strategy of China}

China's rural population comprises $70 \%$ of the total population; if there is no modernization of rural areas, there will be no modernization of the country. With China's rural economic development and accelerated urbanization process, rural energy consumption will be the primary source of China's future carbon emissions 
growth. Large-scale biofuel is an available alternative for transportation fuels (Cong et al., 2017). By promoting the world's leading ecological cycle economy-clean energy model, DQY aims to collect the methane from the fermentation of common manure and straw for power generation, so as to meet basic rural production and living demands. This will not only meet part of the rural and urban energy demands but also help to solve rural straw burning, water pollution, animal waste and other environmental problems. The development model of DQY is consistent with the rural renewable energy strategy of China.

\section{(4) Animal welfare}

Among the elements of a living creature's welfare, basic material conditions such as health and so on are fundamental. Like human beings, the welfare of animals should be taken into consideration (Cong and Termansen, 2016), including not suffering from hunger, injuries and poor living condition, in addition to other considerations.

The DQY Ecological Farm, with its ecological cycle system of sustainable development and protection of the natural environment, continuously improves animal welfare to achieve harmony between human and nature. To prevent the incidence of infectious diseases and secure baby chick's health, DQY monitors the antibody levels in the chicks after each vaccination to ensure effectiveness and uniformity. Fully automatic environmental control systems are installed in every chicken house. Water and feed, ventilation, egg collection, lightning, temperature, humidity and manure collection are all computer-controlled. The temperature inside the houses is set between 22 and $28^{\circ} \mathrm{C}$. The entire poultry operation adopts advanced technology and high standards, paying full respect for animal welfare.

\subsection{Comprehensive development model of Chinese biogas}

Household biogas projects are the main component of biogas production in China. However, now the growth of Chinese household biogas has stalled. It is necessary to design a comprehensive biogas model in China (Fig. 6). 


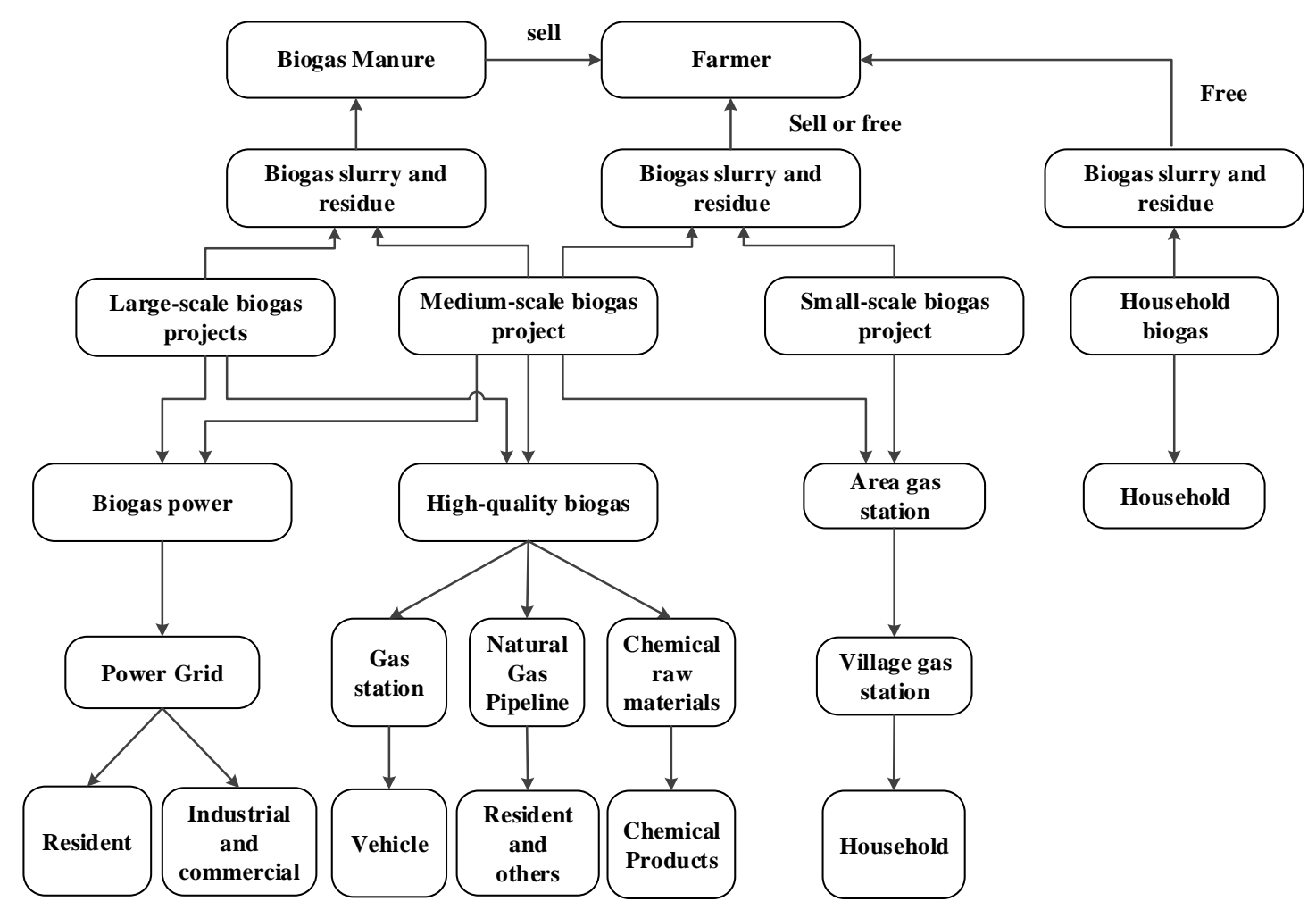

Fig. 6. Comprehensive development model of Chinese biogas in the future

In order to better promote the circular economy development of Chinese biogas, we must:

(1) In order to obtain high quality biogas, raw biogas should be removed impurities and purification. High quality biogas with a clean, high-energy characteristics, is primarily used in three ways: into the gas station as the vehicle fuel, natural gas pipeline into the city or as the chemical raw materials. High quality biogas is the main direction of future development of biogas industry in China.

(2) A large amount of biogas from the large and medium-scale biogas projects can be used for the biogas power generation and further into the national grid, which enables long-distance transmission of energy. We should insist on development of the biogas industry, especially large and medium-scale comprehensive biogas projects, inspired by the DQY model.

(3) Now Chinese biogas projects meet with a series of problems, such as the high rate of abandoned pools, poor related industries, the great gap between urban and rural development and other issues .It is necessary to design a path to utilize waste resources in rural areas more efficiently and also provide clean energy for rural 
people.

Through promoting the development of medium and small-scale biogas projects in rural areas which have abundant biomass waste resources, compressed biogas can be supplied for village households from the gas central station. It is very convenience for feedstock supply, and high quality compressed biogas from the central station can be transported to the village gas station with trucks without a need for separate pipeline construction. The biogas from village to households is flexible, although the population concentrated areas could need pipeline construction. With gradually improving the quality of rural roads in China, village biogas supply station maybe become a good choice in the future.

\section{Conclusions and recommendations}

\subsection{Conclusions}

The large scale utilization of fossil energy has led to an increase in greenhouse gas emissions, and China faces increasing pressure to reduce their emissions of greenhouse gases. Developing the biomass industry is one of the most far-reaching means to reduce greenhouse gas emissions. Biogas is an ideal way to produce renewable energy by utilizing waste products.

As the first large-scale biogas project in the world that utilizes $100 \%$ chicken manure as a feedstock, DQY is designed to apply advanced biogas technologies as a comprehensive circular economy model. DQY creates an exemplary model of contract agriculture by organically integrating the production of biogas with livestock operations, ecological agriculture, manure production and surrounding households and markets. Specifically, we find that

(1) The DQY biogas project has sound economic benefits. The DQY biogas project realizes RMB 4 million yuan per year from power generation and biogas fertilizer sales. If selling greenhouse gas emission reduction credits is taken into account, DQY gains another RMB 8 million yuan per year.

(2) The DQY biogas project has significant environmental benefits. The DQY project has potentials in reducing 84,000 tons of $\mathrm{CO} 2$ annually and 2,600 tons of 
gravel in chicken manure with a removal rate of $89 \%$.

(3) The DQY biogas project has positive social impacts. The DQY project promotes employment through directly providing 10 jobs and indirectly providing 390 jobs in other parts of Ecological Garden.

The DQY Ecological Farm, in particular, operates as a low-carbon model and realizes the circular use of a resource. Throughout the entire production process, animal welfare is completely respected. The components mentioned above are key components of a new rural energy strategy in China.

\subsection{Recommendations}

China needs to find a better balance betwwen its rapid economic development and continuously increased energy consumption (Fan et al., 2016; Zhang et al., 2015). Chinese agriculture is under a reform where more environment-friendly manure collection and processing practices are introduced to diminish air and water pollution (Zheng et al., 2014). Developing biomass energy is not only an important way to reduce fossil fuel use and greenhouse gas emissions, but also a key component to develop an ecological agriculture and a circular economy.

We suggest that the Chinese government and private enterprises should consider the success of the DQY project as an example and increase funding and technical support for additional biogas and circular economy projects, reinforce the use of recycled materials in renewable energy production, and reduce environmental pollution and emissions of greenhouse gases.

Although developing biomass energy in China has multiple benefits, we should also keep the potential problems in mind. One of them is the optimal design of biogas plant varies according to local conditions, e.g. feedstock supply and local infrastructure (Batzias et al., 2005). Another problems is initial investment of biogas system could be high for economically weak rural regions, which requires policy and financial supports such as investment subsidies (Lantz et al., 2007) and targeted loans (Cong and Brady, 2012). 


\section{References:}

Abouelenien, F., Fujiwara, W., Namba, Y., Kosseva, M., Nishio, N., Nakashimada, Y., 2010. Improved methane fermentation of chicken manure via ammonia removal by biogas recycle. Bioresource technology 101, 6368-6373.

Andersen, M.S., 2007. An introductory note on the environmental economics of the circular economy. Sustainability Science 2, 133-140.

Balachandra, P., 2011. Modern energy access to all in rural India: An integrated implementation strategy. Energy Policy 39, 7803-7814.

Batzias, F., Sidiras, D., Spyrou, E., 2005. Evaluating livestock manures for biogas production: a GIS based method. Renewable Energy 30, 1161-1176.

Bruni, E., Jensen, A.P., Angelidaki, I., 2010. Comparative study of mechanical, hydrothermal, chemical and enzymatic treatments of digested biofibers to improve biogas production. Bioresource technology 101, 8713-8717.

Carrère, H., Sialve, B., Bernet, N., 2009. Improving pig manure conversion into biogas by thermal and thermo-chemical pretreatments. Bioresource Technology 100, 3690-3694.

Castrillón, L., Fernández-Nava, Y., Ormaechea, P., Marañón, E., 2011. Optimization of biogas production from cattle manure by pre-treatment with ultrasound and co-digestion with crude glycerin. Bioresource technology 102, 7845-7849.

Chae, K., Jang, A., Yim, S., Kim, I.S., 2008. The effects of digestion temperature and temperature shock on the biogas yields from the mesophilic anaerobic digestion of swine manure. Bioresource Technology 99, 1-6.

Chang, I.-S., Zhao, J., Yin, X., Wu, J., Jia, Z., Wang, L., 2011. Comprehensive utilizations of biogas in Inner Mongolia, China. Renewable and Sustainable Energy Reviews 15, 1442-1453.

Chen, R., 1997. Livestock-biogas-fruit systems in South China. Ecological Engineering 8, 19-29.

Chen, Y., Yang, G., Sweeney, S., Feng, Y., 2010. Household biogas use in rural China: a study of opportunities and constraints. Renewable and sustainable energy reviews 14 , 545-549.

Cong, R.-G., 2013. An optimization model for renewable energy generation and its application in China: a perspective of maximum utilization. Renewable and Sustainable Energy Reviews 17, 94-103.

Cong, R.-G., Brady, M., 2012. How to design a targeted agricultural subsidy system: efficiency or equity? PloS one 7, e41225.

Cong, R.-G., Shen, S., 2014. How to develop renewable power in China? A cost-effective perspective. The Scientific World Journal 2014.

Cong, R.-G., Termansen, M., 2016. A bio-economic analysis of a sustainable agricultural transition using green biorefinery. Science of the Total Environment 571, 153-163.

Cong, R.-G., Wei, Y.-M., 2012. Experimental comparison of impact of auction format on carbon allowance market. Renewable and Sustainable Energy Reviews 16, 4148-4156. 
Cong, R., Caro, D., Thomsen, M., 2017. Is it beneficial to use biogas in the Danish transport sector?-an environmental-economic analysis. Journal of Cleaner Production.

Demirbas, A., 2004. Combustion characteristics of different biomass fuels. Progress in energy and combustion science 30, 219-230.

Fan, J.-L., Zhang, Y.-J., Wang, B., 2016. The impact of urbanization on residential energy consumption in China: An aggregated and disaggregated analysis. Renewable and Sustainable Energy Reviews.

Feng, T., Cheng, S., Min, Q., Li, W., 2009. Productive use of bioenergy for rural household in ecological fragile area, Panam County, Tibet in China: The case of the residential biogas model. Renewable and Sustainable Energy Reviews 13, 2070-2078.

Gao, M., Liang, F., Yu, A., Li, B., Yang, L., 2010. Evaluation of stability and maturity during forced-aeration composting of chicken manure and sawdust at different $\mathrm{C} / \mathrm{N}$ ratios. Chemosphere 78, 614-619.

Geng, Y., Fu, J., Sarkis, J., Xue, B., 2012. Towards a national circular economy indicator system in China: an evaluation and critical analysis. Journal of Cleaner Production 23, 216-224.

Gokcol, C., Dursun, B., Alboyaci, B., Sunan, E., 2009. Importance of biomass energy as alternative to other sources in Turkey. Energy Policy 37, 424-431.

He, Y., Xu, Y., Pang, Y., Tian, H., Wu, R., 2016. A regulatory policy to promote renewable energy consumption in China: Review and future evolutionary path. Renewable Energy 89, 695-705.

Hua, Y., Oliphant, M., Hu, E.J., 2016. Development of renewable energy in Australia and China: A comparison of policies and status. Renewable Energy 85, 1044-1051.

Jiang, D., Zhuang, D., Fu, J., Huang, Y., Wen, K., 2012. Bioenergy potential from crop residues in China: Availability and distribution. Renewable and sustainable energy reviews $16,1377-1382$.

Jiang, X., Sommer, S.G., Christensen, K.V., 2011. A review of the biogas industry in China. Energy Policy 39, 6073-6081.

Karpenstein-Machan, M., 2001. Sustainable cultivation concepts for domestic energy production from biomass. Critical Reviews in Plant Sciences 20, 1-14.

Lantz, M., Svensson, M., Björnsson, L., Börjesson, P., 2007. The prospects for an expansion of biogas systems in Sweden-incentives, barriers and potentials. Energy policy 35, 1830-1843.

Matsuo, N., 2003. CDM in the Kyoto negotiations. Mitigation and Adaptation Strategies for Global Change 8, 191-200.

Minister of Agriculture, P., 2015. China Agricultural Statistics. China Agriculture Press, Beijing.

Qi, X., Zhang, S., Wang, Y., Wang, R., 2005. Advantages of the integrated pig-biogas-vegetable greenhouse system in North China. Ecological Engineering 24, 175-183.

Shuit, S.H., Tan, K.T., Lee, K.T., Kamaruddin, A., 2009. Oil palm biomass as a sustainable energy source: A Malaysian case study. Energy 34, 1225-1235.

Sutter, C., Parreño, J.C., 2007. Does the current Clean Development Mechanism (CDM) 
deliver its sustainable development claim? An analysis of officially registered CDM projects. Climatic change 84, 75-90.

Wang, X., Yang, G., Feng, Y., Ren, G., Han, X., 2012. Optimizing feeding composition and carbon-nitrogen ratios for improved methane yield during anaerobic co-digestion of dairy, chicken manure and wheat straw. Bioresource Technology 120, 78-83.

Zhang, Y.-J., Bian, X.-J., Tan, W., Song, J., 2015. The indirect energy consumption and CO 2 emission caused by household consumption in China: an analysis based on the input-output method. Journal of Cleaner Production.

Zheng, C., Bluemling, B., Liu, Y., Mol, A.P., Chen, J., 2014. Managing manure from China's pigs and poultry: The influence of ecological rationality. Ambio 43, 661-672. 